This is an Author's Original Manuscript of an article published in special issue 'Diffracted Worlds, Diffractive Reading: Onto-Epistemologies and the Critical Humanities' (eds. B Kaiser and K Thiele) Parallax, 20:3 (issue 72): 165-167 (DOI: 10.1080/13534645.2014.927621) [to quote, please consult the published version]

\title{
Diffraction: Onto-Epistemology, Quantum Physics and the Critical Humanities
}

\author{
Birgit Mara Kaiser and Kathrin Thiele
}

\author{
It matters what matters we use to think other matters with; \\ it matters what stories we tell to tell other stories with; it matters \\ what knots knot knots, what thoughts think thoughts, what ties tie ties. \\ It matters what stories make worlds, what worlds make stories. ${ }^{1}$
}

In critical cultural analysis, the metaphor of 'diffraction' surfaced in 1992 with Donna Haraway's 'The Promises of Monsters' as a feminist tool to rethink difference/s beyond binary opposition/s. ${ }^{2}$ Drawing on physical optics, where it describes the interference pattern of diffracting light rays, Haraway adopted diffraction to move our images of difference/s from oppositional to differential, from static to productive, and our ideas of scientific knowledge from reflective, disinterested judgment to mattering, embedded involvement. It is an 'invented category of semantics' ${ }^{3}$ that builds on and contests metaphors we habitually use to describe as practices of knowing and living. Diffraction, thus, is a significant 'subject-shifter'. ${ }^{4}$ It shifts the subjects of critique and if we leap to Karen Barad's quantum understanding of diffraction - it even shifts the foundational ontological and epistemological presuppositions that condition these subject-formations. With Barad's quantized diffraction, a relational ontology emerges that can no longer be categorically separated from its epistemological processes. Quantized diffraction becomes 'entangled': as both method of engagement and radically immanent world(ing) where relationality/differentiation are primary dynamics of all material-discursive entanglements. Ontology and epistemology become inter-/intra-laced as onto-epistemology. ${ }^{5}$

Drawing on Niels Bohr's Copenhagen interpretation, Barad highlights the (uncanny) inseparability of the queer behaviour of matter evidenced on a quantum level and our practices of (scientific) observation, knowledge and 'meaning-mattering'. The quantumphysical 'two-slit diffraction experiment' was for Bohr a thought-experiment to determine if light was particle (as classically held by Newton) or wave (as experimentally shown by Young in 1803). It made evident that under certain conditions (if it remains unclear through which slit the photon passes) the results are a wave pattern, while under other conditions (if the photon's path is defined by a 'which-path detector') light behaves like a particle. ${ }^{6}$ One crucial point of this quantum mechanical paradox - with far reaching implications - is that 'the nature of the observed phenomenon changes with corresponding changes in the apparatus' ${ }^{7}$ The transparency of measurement assumed in classical physics and reflexive theories of knowledge are thereby toppled. Measurement matters, and it does so not only in the supposedly small-scale, weird world of quanta. As Vicki Kirby notes, the full implications of the insight that 'the very ontology of the entities emerges through relationality' still need to be fathomed for 'life at large'. 
This is an Author's Original Manuscript of an article published in special issue 'Diffracted Worlds, Diffractive Reading: Onto-Epistemologies and the Critical Humanities' (eds. B Kaiser and K Thiele) Parallax, 20:3 (issue 72): 165-167 (DOI: 10.1080/13534645.2014.927621) [to quote, please consult the published version]

Diffraction is attractive - also to this special issue - as alternative vocabulary and different technology for critical inquiries: as an image of thought and - or better even 'as' - a praxis of analysis that foregrounds differentiality; provides alternatives to 'reflection' as metaphor for our epistemologies; affirms our knowledge-practices as mattering hereand-now and not merely recording after-the-fact; and highlights the fundamental material relationality of a diffracted/-ing world at the turn of this new millennium. The desire to re-trope our tools of meaning-making and analysis is fuelled by the bio-/necropolitical, neoliberal realities of our present. In order to analyse these complex realities, we need to become literate with-in them. Interlacing the nature/s of matter/s with knowledge/s of/in it, diffraction highlights the systemic intra-actions and unavoidable 'agential cuts' that co-constitute subjects, objects and the ongoing pattern-formations in which they/we participate. Theorizing onto-epistemologies is neither leading into an accelerated subjective constructivism, nor an object-oriented rejection of (human) agency or responsibility. Onto-epistemology departs from discrete, given entities as units of analysis and considers agential forces (selves, cultures, objects, etc.) as processually, relationally and asymmetrically produced (all at once).

The contributions to this special issue highlight the impact that such thinking-withdiffraction can have (or will always/already have had) for the humanities, inviting scholars to reconsider the categorical frameworks, driving metaphors and logic of causality still operative in humanities research, even if implicitly. To develop a critical toolbox in the diffractive mode for our studies of world(ing)s seems to us one of the major tasks for future humanities research. To develop literacies for-from-with-in the changing economic, ecological, digital and scientific landscapes and our complex (cultural-economic-ecologico-socio-political) co-dependencies is pressing. In order to be up to this task, we need to sharpen our tools. A potential subject-shifter like diffraction is here very welcome. Welcoming it does not signal the desire to be adopted by the sciences. Rather, it indicates the openness to affirmative-critical devices that disrupt, intervene and cut-together-apart (diffract) meaning-mattering processes in this still rather young twenty-first century.

\section{Notes}

${ }^{1}$ Donna Haraway, 'SF: Science Fiction, Speculative Fabulation, String Figures, So Far', Pilgrim Award Acceptance Comments, 2011, $<$ http://people.ucsc.edu/ haraway/Files/PilgrimAcceptanceHaraway.pdf $>$ [30/01/2014].

2 Donna Haraway, 'The Promises of Monsters: A Regenerative Politics for Inappropriate/d Others' in The Haraway Reader (London: Routledge, 2004), pp.63-124.

${ }^{3}$ Donna Haraway, Modest_Witness@Second_Millenium.FemaleMan_Meets_OncoMouse ${ }^{T M}(\mathrm{New}$ York/London: Routledge, 1997), p.16.

${ }^{4}$ Donna Haraway, 'The Promises of Monsters', p.64.

${ }^{5}$ Karen Barad, Meeting the Universe Halfway. Quantum Physics and the Entanglement of Matter and Meaning (Durham: Duke University Press, 2007).

${ }^{6}$ See Karen Barad, Meeting the Universe Halfway, pp.71-131, 247-352; also Niels Bohr, 'Discussion with Einstein on Epistemological Problems in Atomic Physics' in Atomic Physics and Human Knowledge (New York: Dover, 2010), pp.32-66. 
This is an Author's Original Manuscript of an article published in special issue 'Diffracted Worlds, Diffractive Reading: Onto-Epistemologies and the Critical Humanities' (eds. B Kaiser and K Thiele) Parallax, 20:3 (issue 72): 165-167 (DOI: 10.1080/13534645.2014.927621) [to quote, please consult the published version]

${ }^{7}$ Karen Barad, Meeting the Universe Halfway, p.106.

${ }^{8}$ Vicki Kirby, Quantum Anthropologies: Life at Large (Durham: Duke University Press, 2011), p.76. The potent/ial effects of such shifts in theory, method and praxis have recently been also explored in Stacey Alaimo and Susan Hekman (eds.), Material Feminisms (Bloomington: Indiana University Press 2008); Rick Dolphijn and Iris van der Tuin, New Materialism: Interviews and Cartographies, Open Humanities Press, 2012. 